\title{
Cerebral herniation during bacterial meningitis in children
}

\author{
Gordon Rennick, Frank Shann, John de Campo
}

\begin{abstract}
Objective-To see whether the incidence of cerebral herniation is increased immediately after lumbar puncture in children with bacterial meningitis and whether any children with herniation have normal results on cranial computed tomography.

Design-Retrospective review of case notes; computed tomograms were read again.

Setting-Large paediatric teaching hospital.

Subjects-445 children over 30 days old admitted to hospital with bacterial meningitis.

Main outcome measures-Timing of herniation in relation to lumbar puncture; findings on computed tomography in children with herniation.

Results-Cerebral herniation was detected in 19 $(4 \cdot 3 \%)$ of the 445 children (21 episodes; herniation occurred twice in two children). Herniation occurred in $14(45 \%)$ of the 31 children who died. Nineteen episodes of herniation occurred in the 17 children who had a lumbar puncture; 12 of the episodes occurred in the first 12 hours after the lumbar puncture and seven over six other 12 hour periods (odds ratio 32.6 (95\% confidence interval 8.5 to 117.3$) ; p<0.001$ ). The results of cranial computed tomography were normal in five $(36 \%)$ of the 14 episodes of herniation in which scanning was performed at about the time of herniation.

Conclusions-The temporal relation between lumbar puncture and herniation strongly suggests that a lumbar puncture may cause herniation in some patients, and normal results on computed tomography do not mean that it is safe to do a lumbar puncture in a child with bacterial meningitis.
\end{abstract}

\section{Introduction}

Cerebral or cerebellar herniation (coning) is a catastrophic complication of bacterial meningitis with a high risk of fatal outcome or long term results. Herniation can occur soon after diagnostic lumbar puncture, ${ }^{1-4}$ but whether lumbar puncture causes herniation is controversial. This has led to conflicting recommendations about when to perform lumbar puncture in an unconscious child who may have meningitis; some suggest that it should be done immediately in any child suspected of having meningitis ${ }^{5}$ and others that cranial computed tomography should be performed before lumbar puncture. ${ }^{0-8}$

We reviewed the histories of children with meningitis and cerebral herniation at a large urban teaching hospital to determine, firstly, whether the incidence of cerebral herniation immediately after lumbar puncture was increased and, secondly, whether any children with herniation had normal results on computed tomography.

\section{Patients and methods}

This hospital is the paediatric referral centre for a population of about 4.5 million people; patients managed at the hospital are sicker than average because many uncomplicated cases are treated at peripheral hospitals. The medical records department supplied a list of all children over 30 days old who were discharged with a diagnosis of bacterial meningitis in the six years from 1984 to 1989 . We assumed that children with cerebral herniation would have either died or lived and had cranial computed tomography or been admitted to the intensive care unit; the medical records of all children in these three categories were reviewed by one of us (GR).

The hospital has written indications for lumbar puncture (Emergency Department clinical manual, unpublished). The guidelines state that deep coma (Glasgow coma score $<8$ ) is a contraindication to lumbar puncture. In febrile children with no clear focus of infection the manual suggests that lumbar puncture should be performed in those under 3 months old if they have a temperature over $38^{\circ} \mathrm{C}$ and in those aged 3 months to 2 years if they are lethargic and have a temperature over $38.9^{\circ} \mathrm{C}$. The manual suggests that lumbar puncture should be performed after a febrile convulsion if there is no clear focus of infection in a child under 18 months old and in a child of any age if there is meningeal irritation.

Herniation was defined as having occurred either when it was found at postmortem examination or when at least three of the following five clinical criteria were present: (a) depression of the conscious state so that the child was difficult to rouse or unrousable; $(b)$ one or both pupils dilated or unreactive to light; (c) hyperventilation, irregular respiration (including CheyneStokes respiration), apnoeas, or respiratory arrest; (d) decorticate posture, decerebrate posture, or complete flaccidity; and (e) endotracheal intubation and mechanical ventilation instituted as soon as possible after recognition of these findings. An exception was made if the child was already intubated and paralysed, which limited the available response to whether one or both pupils were dilated or unreactive to light $(b)$. Cerebral herniation was not diagnosed if there was transitory deterioration associated with convulsions. Herniation was deemed to have occurred at the time at which clinical deterioration was first recognised.

The tomograms from the children with herniation and those from an equal number of children without herniation were reviewed by an experienced paediatric radiologist (JdeC) who did not know which children had herniation. The tomograms were classed as normal or abnormal by review of the appearance of the brain parenchyma (density of cerebrum, basal ganglia, and cortex; grey-white differentiation; cerebrum to cerebellar ratio), the ventricles (size of the lateral and third ventricles; size of the fourth ventricle), the cisterns (size of the suprasellar, prepontine, cerebellopontine angle, and midbrain cisterns and of the cisterna magna), the sutures (presence of splitting on scout film), and the foramen magnum (normal or full). The original report was used for two tomograms that could not be obtained for review. 


\section{Results}

During the study 445 children over 30 days old were discharged from the hospital with a diagnosis of bacterial meningitis; their geometric mean age was 2.0 years (range 4 months to 15 years). Thirty one children died and another 127 children were admitted to intensive care or had cranial computed tomography, or both; the records of 157 of these 158 children were available for review.

Cerebral herniation occurred in $19(4.3 \%)$ of the 445 children, and $14(74 \%)$ of the 19 children with herniation died (table I). Herniation occurred on two separate occasions in two of the 19 children (cases 5 ( $a$ and $b$ ) and 10 ( $a$ and $b)$ ). Herniation was not found at postmortem examination in a 22 month old child (case 13) who satisfied four of the five clinical criteria for herniation (he had normal posture), but the examination did show necrosis of the cerebellar tonsils and haemorrhage of the brain stem. The figure shows the time from lumbar puncture to herniation in the 19 episodes of herniation in the 17 children with herniation who had a lumbar puncture; 12 of the 19 herniations occurred in the first 12 hours after lumbar puncture, whereas the seven others occurred over six other 12 hour periods $(p<0.001$, two tailed Fisher's exact test; odds ratio 32.6 (95\% confidence interval 8.5 to $117 \cdot 3)) .{ }^{9}$ Herniation occurred within three hours of lumbar puncture in eight children. At the time of lumbar puncture three children were unresponsive to pain (cases 7, 10a, and 13); three children were drowsy but rousable, one (case 8 ) had a purpuric rash and clonus of the right ankle, another (case 9) had stiffness

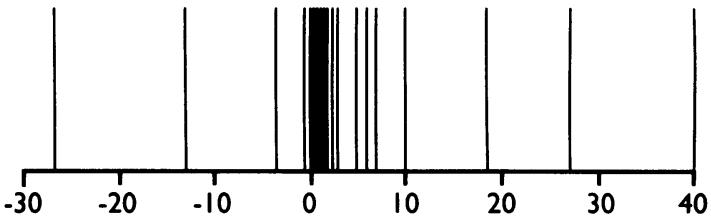

Time from lumbar puncture to herniation (hours)

Time from lumbar puncture to cerebral herniation in 19 episodes of herniation in 17 children who had lumbar puncture performed. Lumbar puncture was performed at time $=0$; negative values indicate that herniation occurred before lumbar puncture

of the neck, and the last (case 11) had decerebrate posturing and a rash); one child had had dilatation of one pupil before being paralysed and ventilated (case $5 \mathrm{~b}$ ); and one child with hypotonic cerebral palsy was hard to assess (case 12). The organism causing meningitis was Haemophilus influenzae type $b$ in 11 of the 19 children with herniation (cases $1-4,6,7,9,10$, 16,17 , and 19), Streptococcus pneumoniae in four (cases $5,13,14$, and 15), Neisseria meningitidis in two (cases 8 and 11), Escherichia coli in one (case 12), and unknown in one (case 18).

Computed tomography was performed at about the time of herniation on 14 occasions, and five of the tomograms yielded normal results $(36 \%(13 \%$ to $65 \%)$ ). The five tomograms with normal results were from four children (herniation occurred twice in one child): two of the children had herniation confirmed at postmortem examination and the other two survived (table I). Table II gives details of eight of the nine

TABLE I-Clinical details of 21 episodes of cerebral herniation in 19 children, including details of postmortem examination, lumbar puncture, and cranial computed tomography

\begin{tabular}{|c|c|c|c|c|c|c|c|c|c|}
\hline Case No & Age & $\begin{array}{c}\text { Signs of } \\
\text { herniation }\end{array}$ & Convulsions & Died & $\begin{array}{l}\text { Herniation found at } \\
\text { postmortem } \\
\text { examination }\end{array}$ & $\begin{array}{l}\text { Time from lumbar puncture } \\
\text { to herniation (min) }\end{array}$ & $\begin{array}{l}\text { Time from herniation to } \\
\text { computed tomography (min) }\end{array}$ & $\begin{array}{l}\text { Abnormal } \\
\text { results on } \\
\text { computed } \\
\text { tomography }\end{array}$ & $\begin{array}{c}\text { Intracranial } \\
\text { pressure } \\
(\mathrm{mm} \mathrm{Hg})\end{array}$ \\
\hline \multicolumn{10}{|c|}{ Herniation without lumbar puncture of before lumbar puncture } \\
\hline 1 & 17 Months & $(a),(b),(c),(d),(e)$ & No & Yes & Yes & No lumbar puncture & 120 & No* & - \\
\hline 2 & 5 Years & $(a),(b),(c),(d),(e)$ & No & Yes & Yes & No lumbar puncture & 90 & Yes* & - \\
\hline 3 & 3 Years & $(a),(b),(c)$ & Yes & Yes & No necropsy & $-1605 \dagger$ & 255 & Yes & 80 \\
\hline 4 & 2 Years & $(a),(b),(c),(e)$ & No & No & - & $-780 t$ & 900 & No & - \\
\hline $5 \mathbf{a}$ & 15 Years & $(a),(b),(e)$ & No & Yes & Yes & $-210 t$ & 150 & No & 75 \\
\hline 6 & 6 Years & $(a),(b),(c),(d),(e)$ & No & Yes & No necropsy & $30 \dagger$ & 330 & Yes & - \\
\hline \multicolumn{10}{|c|}{ Hermiation within three hours of lumbar puncture } \\
\hline 7 & 20 Months & $(a),(b),(e)$ & Yes & Yes & No necropsy & 5 & 120 & Yes & 40 \\
\hline 8 & 15 Years & $(a),(b),(c),(e)$ & Yes & Yes & No necropsy & 20 & 100 & Yes & - \\
\hline $5 \mathrm{~b}$ & 15 Years & (b) $\ddagger$ & Noł & Yes & Yes & 30 & $-90 t t$ & No & 75 \\
\hline 9 & 16 Months & $(a),(b),(e)$ & No & No & - & 60 & 135 & No & - \\
\hline $10 a$ & 3 Years & $(a),(c),(d),(e)$ & No & Nos & - & 60 & 1080 & Yes & - \\
\hline 11 & 15 Months & $(a),(b),(c),(e)$ & No & Yes & No necropsy & 60 & No computed tomography & - & - \\
\hline 12 & 9 Months & $(a),(b),(c),(e)$ & No & Yes & No necropsy & 150 & No computed tomography & - & - \\
\hline 13 & 22 Months & $(a),(b),(c),(e)$ & No & Yes & Equivocal & 180 & No computed tomography & - & - \\
\hline \multicolumn{10}{|c|}{ Herniation more than three hours after lumbar puncture } \\
\hline 14 & 6 Months & $(a),(c),(e)$ & No & Noll & - & 300 & 390 & Yes & 15 \\
\hline 15 & 4 Months & $(a),(b),(c),(e)$ & No & Noll & - & 360 & No computed tomography & - & - \\
\hline 16 & 20 Months & $(a),(c),(e)$ & Yes & Yes & Yes & 420 & No computed tomography & - & - \\
\hline 17 & 4 Months & $(a),(c),(e)$ & Yes & Yes & Yes & 600 & No computed tomography & - & - \\
\hline 18 & 4 Years & $(a),(b),(c),(e)$ & No & Yes & No necropsy & 1110 & No computed tomography & - & - \\
\hline 19 & 19 Months & $(a),(b),(c),(e)$ & No & Yes & No necropsy & 1620 & 540 & Yes & - \\
\hline $10 \mathrm{~b}$ & 3 Years & $(a),(b),(c),(e)$ & No & Nos & - & 2430 & 180 & Yes & - \\
\hline
\end{tabular}

$(a)=$ difficult to rouse or unrousable; $(b)=$ pupils fixed or dilated; $(c)=$ abnormal respiration; $(d)=$ abnormal posture; $(e)=$ given ventilation.

* Original report used as films unavailable for review.

† Negative values indicate herniation occurred before lumbar puncture.

t† Negative value indicates computed tomography performed before herniation occurred.

$\neq$ Paralysed and ventilated at time of deterioration.

$\S$ Residual deafness and behavioural problems at follow up.

\| Discharged with severe neurological impairment.

TABLE II-Findings on computed tomography in eight of nine children with abnormal results (one scan was not available)

\begin{tabular}{|c|c|c|c|c|c|c|c|c|}
\hline & \multicolumn{8}{|c|}{ Case No } \\
\hline & 3 & 6 & 7 & 8 & $10 a$ & $10 \mathrm{~b}$ & 14 & 19 \\
\hline $\begin{array}{l}\text { Cerebrum density } \\
\text { Basal ganglia density } \\
\text { Cortex density } \\
\text { Grey-white differentiation } \\
\text { Cerebrum to cerebellar ratio } \\
\text { Size of: }\end{array}$ & $\begin{array}{l}\text { Low } \\
\text { Normal } \\
\text { Low } \\
\text { Normal } \\
\text { Very abnormal }\end{array}$ & $\begin{array}{l}\text { Low } \\
\text { Normal } \\
\text { Low } \\
\text { Abnormal } \\
\text { Very abnormal }\end{array}$ & $\begin{array}{l}\text { Very low } \\
\text { Normal } \\
\text { Very low } \\
\text { Very abnormal } \\
\text { Very abnormal }\end{array}$ & $\begin{array}{l}\text { Normal } \\
\text { Normal } \\
\text { Normal } \\
\text { Normal } \\
\text { Very abnormal }\end{array}$ & $\begin{array}{l}\text { Normal } \\
\text { Normal } \\
\text { Normal } \\
\text { Normal } \\
\text { Normal }\end{array}$ & $\begin{array}{l}\text { Normal } \\
\text { Normal } \\
\text { Normal } \\
\text { Abnormal } \\
\text { Abnormal }\end{array}$ & $\begin{array}{l}\text { Low } \\
\text { Normal } \\
\text { Low } \\
\text { Very abnormal } \\
\text { Very abnormal }\end{array}$ & $\begin{array}{l}\text { Very low } \\
\text { Normal } \\
\text { Very low } \\
\text { Very abnormal } \\
\text { Normal }\end{array}$ \\
\hline $\begin{array}{l}\text { 3rd and lateral ventricle } \\
\text { 4th ventricle } \\
\text { Sulci } \\
\text { Cisterns } \\
\text { Foramen magnum }\end{array}$ & $\begin{array}{l}\text { Normal } \\
\text { Very small } \\
\text { Very small } \\
\text { Very small } \\
\text { Full }\end{array}$ & $\begin{array}{l}\text { Small } \\
\text { Very small } \\
\text { Very small } \\
\text { Very small } \\
\text { Full }\end{array}$ & $\begin{array}{l}\text { Small } \\
\text { Normal } \\
\text { Very small } \\
\text { Very small } \\
\text { Full }\end{array}$ & $\begin{array}{l}\text { Normal } \\
\text { Small } \\
\text { Very small } \\
\text { Very small } \\
\text { Full?^ }\end{array}$ & $\begin{array}{l}\text { Small } \\
\text { Very small } \\
\text { Very small } \\
\text { Very small } \\
\text { Full }\end{array}$ & $\begin{array}{l}\text { Normal } \\
\text { Very small } \\
\text { Very small } \\
\text { Very small } \\
\text { Full }\end{array}$ & $\begin{array}{l}\text { Very dilated } \\
\text { Very dilated } \\
\text { Very small } \\
\text { Normal } \\
\text { Full }\end{array}$ & $\begin{array}{l}\text { Very small } \\
\text { Very small } \\
\text { Very small } \\
\text { Very small } \\
\text { Full }\end{array}$ \\
\hline
\end{tabular}

${ }^{\star}$ Reduced space but not full. 
abnormal tomograms; the original report was used for the other scan (case 2) as the films were not available.

\begin{abstract}
Discussion
Although all our patients satisfied fairly strict criteria for cerebral herniation, ${ }^{10}$ we cannot be certain that herniation occurred in all of them. The diagnosis was confirmed at postmortem examination in five children. No postmortem examination was performed in eight children who died. Five other children survived. At postmortem examination one child with four of the five clinical signs of herniation had necrosis of the cerebellar tonsils and haemorrhage of the brain stem but no herniation. These findings suggest that herniation may have occurred but was then reversed by the hyperventilation and mannitol that were given to this child during the 17 hours between the clinical diagnosis of herniation and death. The three previous studies of cerebral herniation in children reported 38 cases of herniation, but only five cases were confirmed by postmortem examination. ${ }^{21112}$
\end{abstract}

In our study, eight $(38 \%)$ of the 21 episodes of cerebral herniation occurred within three hours of lumbar puncture and $12(57 \%)$ occurred within 12 hours of lumbar puncture (figure); six (29\%) of the 21 episodes of herniation occurred before lumbar puncture or in a child who did not undergo puncture. The clear temporal relation between lumbar puncture and herniation strongly suggests that the procedure causes herniation in some patients. Possibly lumbar puncture was performed because of a deterioration in clinical state caused by early herniation, but there was no evidence of this just before lumbar puncture in our retrospective review. Horwitz et al found that eight out of 18 cases of herniation occurred within 30 minutes of admission, ${ }^{2}$ suggesting that lumbar puncture may have been the cause, and Dodge and Swartz found that herniation occurred within two hours of lumbar puncture in three out of nine cases diagnosed at postmortem examination. ${ }^{4}$ Rosenberg et al, however, found no relation between lumbar puncture and herniation. ${ }^{1}$

There was an indication to delay lumbar puncture in six of the eight children in our study in whom herniation occurred within three hours of lumbar puncture: three children were unresponsive to pain, two had focal neurological signs, and one had decerebrate posturing. Of the remaining two, one (case 12) had hypotonic cerebral palsy and was hard to assess and the other (case 9) had stiffness of the neck and was drowsy but rousable; she made a good recovery.

In our study computed tomography of the brain yielded normal results in five (36\%) of the 14 episodes of herniation in which a scan was performed at about the time of the herniation. Rosenberg et al reported that nine out of 11 patients with herniation had abnormal results, implying that two $(18 \%)$ had normal results. ${ }^{11}$ Normal results on computed tomography of the brain do not mean that it is safe to do a lumbar puncture in a patient with meningitis.

What are the implications of our study for the management of acutely ill children? We suggest that a clear distinction needs to be made between children who are not severely ill and who will be sent home if the results of a lumbar puncture are normal and children who are so ill that they will be admitted and given antibiotics even if the initial results of a lumbar puncture are normal. The first group of children should have a lumbar puncture at the slightest suspicion of meningitis-for example, moderately ill infants with a temperature over $38.9^{\circ} \mathrm{C}$ and no localising signs. The second group of children should not have a lumbar puncture at the time of presentation; they should be admitted to hospital after starting antibiotics for bacterial meningitis and, if indicated, treatment for other infections such as herpes encephalitis or cerebral malaria. A specimen of urine should be tested for haemophilus and pneumococcus antigens. After the child's clinical state has been stabilised, with intubation and ventilation if indicated, computed tomography may be performed. After two or three days, when the child is fully conscious, a lumbar puncture may be performed if the results of computed tomography are normal. If there are unusual features at the time of presentation or the child's conscious state does not improve rapidly a specimen of cerebrospinal fluid should be obtained from a lateral cerebral ventricle-but ventricular cerebrospinal fluid may be normal in bacterial meningitis.

Our findings strongly suggest that lumbar puncture can cause cerebral herniation in bacterial meningitis and that normal results on cranial computed tomography do not mean it is safe to do a lumbar puncture in a child with meningitis. If meningitis is suspected in a child with decerebrate or decorticate posturing, focal neurological signs, or no response to pain give antibiotics but do not perform lumbar puncture even when a computed tomogram looks normal.

1 Hart IK, Bone I, Hadley DM. Development of neurological problems after lumbar puncture. $B M \mathcal{F} 1988 ; 296: 51-2$.

2 Horwitz SJ, Boxerbaum B, O'Bell J. Cerebral herniation in bacterial meningitis in childhood. Ann Neurol 1980;7:524-8.

3 Harper JR, Lorber J, Hillas-Smith G, Bower BD, Eykyn SJ. Timing of lumbar puncture in severe childhood meningitis. $B M \mathcal{F} 1985 ; 291: 651-2$.

4 Dodge PR, Swartz MN. Bacterial meningitis-a review of selected aspects. II. Special neurologic problems, postmeningitic complications and clinicopathological correlations. N Engl I Med 1965;272:954-60.

5 Fenichel GM. Clinical pediatric neurology: a signs and symptoms approach. Philadelphia: Saunders, 1988:109.

6 Glover $\mathrm{D}$, Smith $\mathrm{AL}$. Increased intracranial pressure in meningitis/encephalitis. In: Morray JP, ed. Pediatric intensive care. Norwalk: Appleton and
longe,

7 Klein JO, Feigin RD, McCracken GH. Report of the task force on diagnosis and management of meningitis. Pediatrics 1986;78:(suppl):959-82.

8 Gower DJ, Baker AL, Bell WO, Ball MR. Contraindications to lumbar puncture as defined by computer cranial tomography. I Neurol Neurosurg Psychiatry 1987;50:1071-4.

9 Armitage P, Berry G. Statistical methods in medical research. 2nd ed. Oxford: Blackwell, 1987:479-80.

10 Plum F, Posner JB. The diagnosis of stupor and coma. Philadelphia: Davis, 1980.

11 Rosenberg DI, McCrory JH, Abhoudon MK, Murante AA, Downs CE. Neuro-intensive care for cerebral herniation in childhood meningitis. In: Hoff JT, Betz AL, eds. Intracranial pressure VII. Berlin: Springer 1989: 770-2. (Proceedings of the seventh international symposium on intracranial pressure.)

12 Benjamin CM, Newton RW, Clarke NA. Risk factors for death from meningitis. BMf 1988;296:20.

(Accepted 4 February 1993)

\section{A MEMORABLE CONSULTANT}

\section{Ruled by a poached egg}

The consultant physician to whom I was housekeeper for 40 years was a man of routine, especially regarding meals. For 40 years I cooked this on Monday, that on Tuesday, and so on, throughout each week, with monotonous regularity. If I suggested a change he took it as a personal affront, making me feel guilty. Once, for sheer devilment. I reversed his breakfasts, giving him Thursday's poached egg on a Tuesday, which, by tradition, was scrambled egg.
He ate his breakfast without comment and went off to his hospital. Later his secretary told me what ensued. Instead of his Tuesday outpatient clinic he went along to do a Thursday's ward round. Seeing the ward was still in a state of early morning bustle, he told the sister, "I see you're not ready for me. I'll come back a little later."

"You are two days early," she pointed out.

"Two days?" he queried. "Isn't it Thursday? It must be. I had poached egg for breakfast."-DONETH BENSON, London 